\title{
Tamizaje serológico y con PCR para determinar la prevalencia de Chlamydia trachomatis en pacientes con vaginosis y vaginitis inespecífica que asisten a hospitales de la Secretaría de Salud de Bogotá
}

\begin{abstract}
Maria Teresa Herrera Mendoza Msc ${ }^{1}$, Ruth Melida Sanchez Msc ${ }^{1}$, Ariel Iván Ruiz Parra MD. Msc. ${ }^{2}$,Olga Lucia Ostos Msc ${ }^{1-3}$.
${ }^{1}$ Universidad Colegio Mayor de Cundinamarca, ${ }^{2}$ Hospital Materno Infantil, ${ }^{3}$ Universidad Antonio Nariño Con la participación de las estudiantes: Gina Paola Ardila Osorio, Catherine del Pilar Diaz, Diana Catherine Gamboa Baez, Marjorie Natalia Acosta Valero, Leonor Edith Barboza Barboza, Yenni M. Agredo Carrillo de la Universidad Colegio Mayor de Cundinamarca. Correspondencia: olostos@unicolmayor.edu.co
\end{abstract}

Recibido: 02-05-2005 / Aceptado: 05-06-2005

\section{Resumen}

Chlamydia trachomatis (CT) es uno de los agentes etiológicos más importantes en las infecciones de transmisión sexual. En la mujer CT causa patologías tales como cervicitis, uretritis y enfermedad pélvica inflamatoria, entre otras. Los objetivos de este trabajo fueron determinar la prevalencia de la infección y la concordancia de las pruebas diagnósticas para CT en pacientes sintomáticas de vaginitis o leucorrea inespecífica, que asistieron al hospital Pablo VI de Bosa y al Hospital del Sur de Bogotá, durante los meses de junio y julio de 2004. Se obtuvieron 180 muestras simultáneas de suero y de orina para la determinación de IgG, IgM e IgA anticlamidia y para PCR, respectivamente. La detección de los anticuerpos para CT en suero se realizó mediante el método ELISA (VIRCEL) y la detección del DNA en orina se hizo con la prueba AMPLICOR CT PCR (ROCHE). La prevalencia de la infección fue del 31\% (56 casos). La mediana de edad en mujeres con evidencia de infección reciente o activa fue de 23 años; 37 pacientes (66\%) positivas para algún marcador tenían infección activa. En 24 participantes $(42.8 \%)$ con infección activa, de acuerdo con los resultados serológicos, no se detectó el DNA en orina; en 14 pacientes ( $25 \%$ de las pacientes positivas en las pruebas serológicas) se encontró el PCR positivo en las muestras de orina. Una prevalencia del $31 \%$ en mujeres sintomáticas indica que la infección por Chlamydia es un problema para la salud pública. Implantar un programa de tamizaje para la búsqueda activa de casos, así como la búsqueda activa de contactos sexuales, reducirá el peso socioeconómico de la infección. La prueba ideal para diagnóstico tanto de cervicitis como de uretritis en el mismo procedimiento deberá utilizar muestra de orina y de cepillado cervical.

Palabras clave: Chlamydia trachomatis, Prevalencia, Cervicitis, Uretritis, Chlamydia trachomatis Elisa IgG/ IgM/IgA, AMPLICOR CT PCR.

\footnotetext{
Abstract

Serologic and PCR screening to determine the prevalence of chlamydia trachomatis in patients with vaginitis and inespecific vaginitis in two public hospitals in Bogota: Chlamydia trachomatis is one of the most important agents in the aetiology of sexually transmitted diseases (STD). In women CT causes cervicitis,
} 
urethritis and pelvic inflammatory disease. The objectives of this investigation were to determine the prevalence of chlamydial infection and the concordance of the diagnostic tests in patients with vaginitis and inespecific vaginitis who assist to two public hospitals of Bogota (Hospital Pablo VI de Bosa and Hospital del Sur), during June and July 2004. IgG, IgM and IgA in serum and PCR in urine samples were practiced in 180 patients. $C$. trachomatis antibodies detection was done by ELISA (VIRCEL) and DNA detection by AMPLICOR CT PCR (ROCHE) test. The prevalence of chlamydial infection was 31\% (56 cases). The median age of women with recent or active infection was 23 years. 37 patients $(66 \%)$ with positive results in at least one marker had active infection. DNA was not detected in urine samples in 24 patients $(42.8 \%)$ with active infection diagnosed by serologic criteria. PCR was positive in urine samples of 14 women ( $25 \%$ of the patients with positive serologic tests). A prevalence of $31 \%$ in symptomatic women indicates a mayor public health problem. It is necessary to implement a screening programme to detect the cases, as well as, to find the sexual contacts in order to reduce the burden of chlamydial infection. A urine sample mixed with a cervical simple will be useful for the simultaneous diagnosis of cervicitis and urethritis.

Key words: Chlamydia trachomatis, Prevalence, Cervicitis, Uretritis, Chlamydia trachomatis Elisa IgG/ IgM/IgA, AMPLICOR CT PCR.

\section{Introducción}

Chlamydia trachomatis es una bacteria Gram negativa intracelular obligada que fue identificada, hace aproximadamente 40 años, como un patógeno exclusivamente humano; desde entonces se le conoce como un importante agente infeccioso de transmisión sexual y perinatal (1-9).

Las infecciones genitales causadas por CT son altamente prevalentes. La Organización Mundial de la Salud informó una prevalencia global del 4.4\%. Se ha reportado una incidencia superior a 50 millones de casos anuales. La transmisión sexual de $C$. trachomatis a menudo excede el $20 \%$ en mujeres adolescentes. La edad de mayor incidencia de las infecciones genitales CT es hacia el final de la adolescencia y comienzos de la edad adulta (4).

Las mujeres afectadas con este agente patógeno son a menudo totalmente asintomáticas y la infección puede persistir durante meses sin producir signos ni síntomas, lo cual puede retardar el diagnóstico (8) y aumentar el riesgo de secuelas a largo plazo, tales como la infertilidad por factor tuboperitoneal. En pacientes con infección gonocócica cervical con frecuencia se observa una infección simultánea por $C T$ La persistencia de la infección en las mujeres jóvenes es importante por dos razones: 1) es considerada como la mayor causa de enfermedad pélvica inflamatoria (EPI), embarazos ectópicos, infertilidad y dolor pélvico crónico y 2) puede ocurrir transmisión perinatal de CT causando conjuntivitis y neumonía en el neonato (15).

La naturaleza asintomática de la infección por CT y la severidad de las complicaciones de la infección con este microorganismo, así como, sus implicaciones en términos económicos para la salud, hacen esencial el tamizaje si se quiere llevar a cabo el control de la enfermedad y la reducción de las secuelas. Para que este tamizaje sea efectivo es necesario utilizar el método más sensible y específico disponible y el método de muestreo que resulte menos invasivo para lograr una adecuada aceptación en la población objeto.

El objetivo de este estudio fue determinar la prevalencia de la infección y la concordancia de las pruebas diagnósticas serológicas con el PCR. Se aplicó una prueba tamiz para detectar anticuerpos en suero de las clases IgG, IgM, e IgA para CT y la detección por amplificación de regiones específicas del plásmido críptico específico de la bacteria en muestras de orina de pacientes sintomáticas de cervicovaginitis o vaginosis inespecífica, que asistieron 
al hospital Pablo VI de Bosa y al Hospital del Sur en Bogotá, durante los meses de junio y julio de 2004.

\section{Materiales y Métodos}

Criterios de inclusión: mujeres con vida sexual activa, con diagnóstico clínico de vaginitis o leucorrea inespecífica que manifestaron en forma escrita su deseo voluntario de participar en el estudio y contestaron la encuesta en relación con variables clínicas de interés.

Población objeto: Mujeres que asistieron a los hospitales Pablo VI de Bosa y del Sur en Bogotá durante el periodo comprendido entre junio y julio de 2004.

\section{Muestras:}

- Suero: se obtuvieron muestras de suero las cuales fueron conservadas a una temperatura de $-20^{\circ} \mathrm{C}$ hasta la fecha de su procesamiento evitando así las congelaciones y descongelaciones innecesarias. Se excluyeron los sueros hiperlipémicos, contaminados o hemolizados.

-Orina: las muestras de orina fueron recolectadas a partir de micción espontánea en el momento de la consulta, en un recipiente plástico estéril y conservada a $-20^{\circ} \mathrm{C}$ hasta la fecha de su procesamiento.

Detección de anticuerpos: se determinaron los anticuerpos de las clases IgG, IgA, IgM anti-C. trachomatis por el método Elisa VIRCELL SL (Italia). Este es un método inmunoenzimático indirecto basado en la reacción de los anticuerpos de la muestra con el antígeno unido a una superficie de poliestireno. Las inmunoglobulinas no unidas por reacción con el antígeno son eliminadas en el proceso de lavado. En un paso posterior la globulina antihumana reacciona con el complejo antígeno-anticuerpo; el anti-anticuerpo no unido, es eliminado por los lavados, mientras que el unido reacciona con el sustrato (TMB), para dar una reacción coloreada azul, que cambia a amarillo tras la

Tabla 1. Interpretación de IgG e IgA en suero

\begin{tabular}{|c|c|c|}
\hline \multicolumn{2}{|c|}{ Posibles resultados } & Interpretación \\
\hline IgG & $\operatorname{lgA}$ & con los sintomas \\
\hline+ & + & Infección activa. Se debe tener en cuenta el título y correlacionar \\
\hline+ & - & Infección reciente o latente \\
\hline+ & $+/-$ & Infección pasada \\
\hline$+/-$ & - & Estadio muy temprano \\
\hline- & + & Infección en un estadio muy temprano o persistencia de IgA \\
\hline- & $+/-$ & Estadio temprano \\
\hline$+/-$ & + & No hay infección \\
\hline- & - & \\
\hline
\end{tabular}

IgM: Infección Activa es la primera vez que se entra en contacto con la bacteria. IgG: Infección pasada.

IgA: Infección activa por contacto secundario. Afección de mucosa vaginal. 
adición de la solución de parada. La sensibilidad y especificidad de la prueba -informadas por el productorson $90 \%$ y $100 \%$ respectivamente. La prueba tiene un coeficiente de variación intraen-sayo de 3.49 e interensayo de 5.33. Las muestras con índices menores o iguales a 0.9 fueron consideradas negativas para anticuerpos clase IgG, IgM e IgA anti-C. trachomatis. Las muestras con índices mayores o iguales a 1.1 fueron consideradas positivas.

Interpretación especifica para $\operatorname{Ig} G$ e $\operatorname{Ig} A$ en suero: la interpretación se hizo de acuerdo con la Tabla 1

Amplificación y detección del plásmido críptico por Reacción en Cadena de la Polimerasa. Esta determinación se hizo con el Test AMPLICOR CT PCR: (Roche Molecular System. E.U). Este es un ensayo automatizado que proporciona un control interno y una mezcla maestra para PCR. El control interno contiene regiones de unión al primer idénticas a los blancos de la C. trachomatis, pero que son detectados con sondas específicas, se amplifican ambos: las regiones específicas del plásmido críptico de CT y el blanco de DNA y, posteriormente se hace una detección selectiva de cada amplicón.

Métodos estadísticos: Los datos obtenidos fueron analizados con el programa STATA 6.0.

\section{Resultados}

En el estudio participaron 180 mujeres. La mediana para la edad fue de 23 años (rango de 15 a 45 años). El $86 \%$ de las participantes no utilizaba métodos anticonceptivos. Dentro del grupo de mujeres usuarias de métodos contraceptivos solo el $40 \%$ utilizaban métodos de barrera (preservativo). El promedio de hijos fue de 1.2 .

Respecto al número de parejas sexuales durante la vida el rango estuvo entre 1 y 15 . El 96\% de las pacientes aseguró no haber cambiado de pareja en los últimos tres meses.
Tabla 2. Distribución porcentual de positividad de los diferentes marcadores para infección por $C$. trachomatis e interpretación

\begin{tabular}{|c|c|c|c|c|c|c|}
\hline $\begin{array}{l}\text { Ig } \\
\text { G }\end{array}$ & $\begin{array}{l}\text { Ig } \\
M\end{array}$ & $\begin{array}{l}\text { Ig } \\
\text { A }\end{array}$ & PCR & $\mathbf{N}^{\circ}$ & $\%$ & Interpretación \\
\hline+ & & - & - & 19 & 33.9 & Infección pasada \\
\hline- & + & - & - & 14 & 25.0 & Infección activa \\
\hline- & - & + & - & 5 & 8.9 & $\begin{array}{c}\text { Infección en estadio } \\
\text { temprano o persistencia } \\
\text { de lgA }\end{array}$ \\
\hline+ & + & - & - & 2 & 3.57 & Infección activa \\
\hline+ & - & + & & 2 & 3.57 & Infección activa \\
\hline- & + & + & - & 1 & 1.78 & Infección activa \\
\hline+ & + & + & + & 1 & 1.78 & Infección activa \\
\hline+ & + & & + & 1 & 1.78 & Infección activa \\
\hline & & + & + & 1 & 1.78 & Infección activa \\
\hline & & & + & 10 & 17.8 & Infección activa \\
\hline \multicolumn{4}{|c|}{ TOTAL } & 56 & 100 & \\
\hline
\end{tabular}

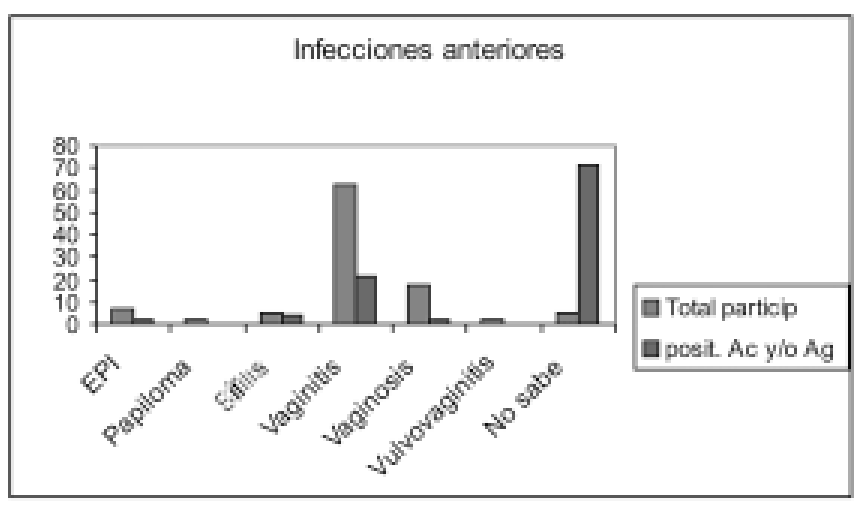

Figura 1. Infecciones vaginales anteriores. total participantes/ participantes con positividad de por lo menos uno de los marcadores

El treinta y uno por ciento de las participantes (56 pacientes) mostró positividad para por lo menos uno de los marcadores de infección por CT. Treinta y siete pacientes $(66 \%)$ positivas para algún marcador tenían infección activa. En 24 participantes (42.8\%) con infección activa, de acuerdo con los resultados serológicos, no se detectó el DNA en orina. En 14 pacientes $(25 \%$ de las pacientes positivas en las pruebas serológicas) se encontró el PCR positivo en las muestras de orina. La Tabla 2 muestra la distribución porcentual de positividad de los diferentes marcadores en la población estudiada.

El $44.5 \%$ del total de participantes manifestó haber padecido una infección vaginal con anterioridad. Este porcentaje se mantuvo en las pacientes que fue- 


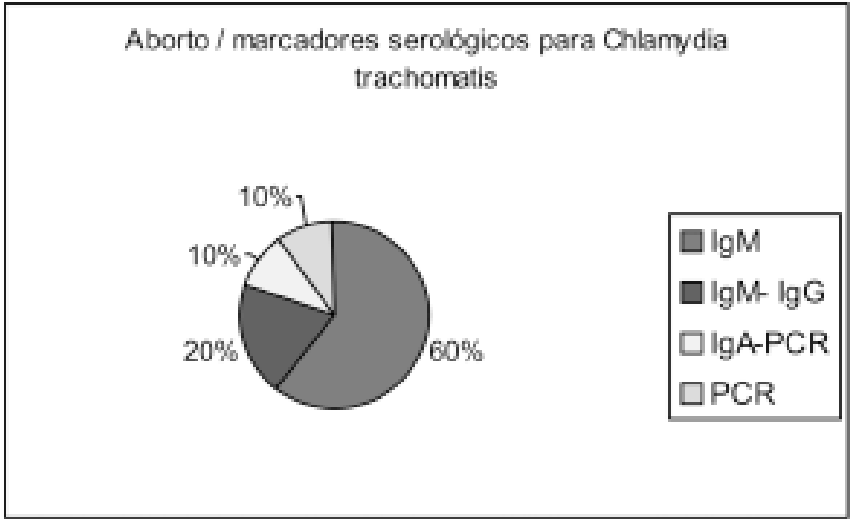

Figura 2. Relación entre los abortos y la positividad de los marcadores para CT.

ron positivas para por lo menos uno de los marcadores. La figura 1 resume comparativamente las infecciones informadas.

El $17.8 \%$ de las pacientes manifestó haber presentado aborto (no se interrogó cuanto tiempo antes de la prueba) la Figura 3 resume la relación entre los abortos y la positividad de los marcadores para CT.

\section{Discusión}

En este estudio se encontró una prevalencia del $31 \%$ de infección por CT en una población de mujeres sintomáticas, con diagnóstico clínico de vaginitis o leucorrea inespecífica. Dada la alta prevalencia se debe considerar el diagnóstico presuntivo de infección por Chlamydia en los casos de patología infecciosa del tracto genital. Un reporte de la KFF en 1998 (10) afirmó que la Chlamydia infecta con facilidad el cuello uterino inmaduro, haciendo que las mujeres adolescentes sean más susceptibles. Eng y Butler en 1997 (8) reportaron en E.U. una prevalencia del 30 al $40 \%$ en mujeres con edades comprendidas entre los 19 y los 25 años; esto concuerda con nuestro estudio en el cual encontramos una mediana de 23 años en las mujeres con infección por Chlamidia.

Llama la atención que solo el $19.44 \%$ de las participantes en el estudio planificaba a pesar de estar en la edad de mayor actividad sexual y que menos de la mitad de quienes practicaban contracepción, utilizaban métodos de barrera a pesar de la información disponible, no obstante el promedio de hijos fue relativamente bajo.

En relación con la detección de los diferentes marcadores para CT, 37 de las pacientes (66\%) que fueron positivas para algún marcador tenían infección activa y en 14 de estas pacientes (37.8 \%) la prueba de PCR permitió realizar el diagnóstico de uretritis. 24 participantes $(42.8 \%)$ fueron positivas para uno o dos marcadores serológicos de infección activa pero no se detectó $\mathrm{CT}$ en la orina lo que presupone solo una infección cervical o en otro sitio del tracto genital. En diez pacientes (20.8\%) la prueba del PCR en orina fué positiva, pero solo en tres $(5.36 \%)$ se obtuvo positividad simultánea para otro marcador serológico. La falta de concordancia en éstos casos puede explicarse por varios factores: en relación con la paciente, la infección de la uretra puede ser tan reciente que no se había producido la respuesta inmunológica, el nivel de anticuerpos producido por el paciente no es adecuado o es tan bajo que no puede ser detectado por la prueba de ELISA utilizada; en relación con la bacteria, esta es un parásito intracelular que no desencadena una adecuada respuesta serológica y, finalmente, en relación con las pruebas utilizadas, el test de ELISA, siendo un buen método por su reproductividad, especificidad y sensibilidad para la investigación de anticuerpos circulantes, solamente es útil en procesos recientes de salpingitis, cervicitis, uretritis no gonocócica, linfogranuloma venéreo y en el primer episodio de la enfermedad. Cuando el proceso se hace crónico es muy difícil demostrar un aumento significativo de anticuerpos circulantes (1). Por otro lado, las técnicas de PCR han demostrado poseer una mayor sensibilidad que el cultivo (11-12), siendo esta mayor o igual en muestras de orina en comparación con muestras endocervicales, probablemente por la presencia de inhibidores en el especimen cervical (2).

Aunque se observó una asociación entre la presencia de inmunoglobulina de clase $\operatorname{IgM}$ y el antecedente de aborto no se puede establecer una 
relación causal ya que no conocemos la relación temporal.

\section{Conclusiones y recomendaciones}

La prevalencia de la infección por CT en la población estudiada fue alta. La detección de $C$. trachomatis continua siendo un desafío debido a que la realización de pruebas en muestras obtenidas de un solo sitio podría no ser sensible para demostrar la infección por este microorganismo. La prueba de PCR en muestras de orina ofrece ventajas por su alta sensibilidad, que a la larga conduce a reducción de costos y porque la muestra, orina, se puede almacenar a temperaturas entre 2 y 8 grados centígrados hasta por 8 días, lo que permite una fácil remisión a laboratorios de referencia.

El test de ELISA para detección de anticuerpo contra CT de clases IgG, IgM e IgA, tiene las siguientes ventajas: es una prueba automatizada en la cual los resultados se obtienen en 90 minutos; se puede procesar un gran número de muestras al mismo tiempo y es altamente sensible y específica; sin embargo, es útil en procesos recientes y en grupos de pacientes donde la prevalencia es alta.

La prueba de PCR es ideal para el diagnóstico tanto de cervicitis como de uretritis en el mismo procedimiento como lo proponen Chan, Brand y colaboradores, quienes recomiendan realizar la prueba en una muestra de orina en la cual se han mezclado células de cepillado endocervical (5). Aunque se requiere para ello utilizar un método invasivo para obtener células cervicales, se garantiza un diagnóstico y un tratamiento oportunos.

Se debe enfatizar que la Infección por CT es asintomática en una proporción importante de pacientes y constituye un serio problema de salud pública. Es necesario implementar programas de tamizaje para la búsqueda activa de casos, así como una notificación de contactos sexuales, que reduzcan la carga de la enfermedad y las secuelas a largo plazo.

\section{Agradecimientos}

Laboratorio ANAR DIAGNOSTICA IMPORT. Quien facilitó su sede, y sus equipos para la realización de este estudio y a la Dra. Edna Margarita Nagles por su asesoría técnica.

\section{Referencias}

1. Basuado JA, Cuto C, De Torres R. Microbiología Biomédica. Ed. Atlante. Buenos Aires, Argentina 1996; 38:420-426.

2. Bauwens JE, Clark AM, Stamm WE, Diagnosis of Chlamydia trachomatis endocervical infections by a commercial polymerase chain reaction assay. J. Clin. Microbiology.1993; 31:3023-3027.

3. Black C. Current Methods of Laboratory Diagnosis of Chlamydia trachomatis Infections. Clinical Microbiology Reviews. 1997; (18): 160 - 184.

4. Centers for Disease Control and Prevention. Guidelines for treatment of sexually transmitted diseases. MMWR. 1998; 47: 1-116.

5. Chan EL, Brandt K, Stoneham B, Antonishyn N, Horsman G, Archivos de Patología y la Medicina del Laboratorio. Northfield. 2000; 124 (6): 840p.

6. Chavez M, Vargas J, Pueyo I, Valverde A, Serrano M, Claro R, Manzuelos ME. Incidencia de la infección genitourinaria por Chlamydia trachomatis en un centro de ETS, estimada mediante detección directa de antígeno. Enferm. Infec. 2000; 18:392-395.

7. Dean D, Suchland R, Stam W. Evidence for Long - term cervical persistence of Chlamydia trachomatis by omp I genotyping. J Infect Dis. 2000; 182:909- 916.

8. Eng T, Butler W. The Hidden Epidemic: confronting sexually transmited diseases. Washington, D.C. National Academy Press.2003.

9. Fauci AS, Braunwald E, Isselbucher K. Principios de medicina Interna. McGrawHill. 1998; 181:1209-1216

10. KFF- Kaiser Family Foundation. Sexually Transmited Diseases in America. How many Cases and what Cost? Mela Park, CA. Kaiser Family Foundation and American Social Health Association. 1998.

11. Labay E, Henry S, Bennet P, Massip P, Chabanon G. Direct Diagnosis of Chlamydia trachomatis Genital Infections: Culture or PCR? Pathol Biol Paris. 1998; 46(10):813-818.

12. Madico G, Quinn TC, Boman J, Gaydos CA. Touch down enzyme time release- PCR for detection and identification of Chlamydia trachomatis, Chlamydia pnemoniae and Chlamydia psittacci using the $16 \mathrm{~S}$ and $16 \mathrm{~S} 23 \mathrm{C}$ Spacer rRNA genes. J Clin Microbiol. 2000; 38:1085 -1093.

13. Morris R, Legault I, and Baker C. Prevalence of isolated uretral asymptomatic Chlamydia trachomatis infection in the absence of cervical infection of in carcelated adolescent girls. Sex Transm Dis. 1993;20:198-200.

14. Pimienta J, Frento K, Tendencias Recientes de las Infecciones por Chlamydia trachomatis en el Reino Unido y Perspectivas de un programa de Detección Nacional. Public. Health Laboratory Service Comunicable Disease Surveillance Centre. Londres Inglaterra. Comm. Dis. Public Health.2003.

15. Sellor JWI, Mahony B, Jang D, et al. Comparison of cervical, urethral, and urine specimens for the detection of Chlamydia trachomatis in women. J Infect Dis. 1998;164:205-208. 
16. Servass AM, Spaargaren J, Schmid G, Pena AS, et. al. Persistence of Chlamydia trachomatis infections: bacterium and hort bast? /.Reply. J Infec Dis. 2001; Vol:184:12:1631.

17. Watson E, Templeton A, Paavonen J, Mardh P, Stary A, Pedeson BS. The accuracy and efficacy of screening test for
Chlamydia trachomatis: a systematic. Review. J Med Microbiol. 2002; (51): 1021 - 1031. 